\title{
EDITORIAL
}

\section{Dirk Willem van Bekkum: a pioneer in haematology, transplantation and radiobiology (1925-2015)}

Leukemia (2015) 29, 2275-2276; doi:10.1038/leu.2015.224

It is difficult for any haematologist, transplant expert or radiobiologist over age 50 years to imagine a world without Dirk van Bekkum. Dirk was more than an expert's expert, he was a force majeure. He described the biology of bone marrow engraftment when it was thought (hard to believe today) post-transplant bone marrow recovery after radiation exposure was endogenous and caused by the transfer of humoral factors (hormones) in the bone marrow graft. He also solved the riddle of graft-versus-host disease (GvHD) by studies in mice and subhuman primates showing it was caused by genetically disparate donor cells attacking the host (hence chimeras after the mythological, firebreathing Greek beast part lion, part goat, part snake). At that time the biology of this post-transplant-related phenomenon was also a mystery and it was termed secondary disease. (Graft-failure/ rejection was termed primary disease.) Several attempts to perform an allogeneic bone marrow transplant in humans had failed until the team of van Bekkum, van Rood, Leo Jan Dooren and Jaak Vossen used a sibling donor and a graft depleted of lymphocytes on a density gradient to decrease the likelihood of GvHD to cure an infant with severe combined immune deficiency disease (SCID). This child, now more than 50 years old and a grandmother, is alive today. At the same time, two other groups in the US were also successful in performing transplants on babies with SCID and Wiskott-Aldrich syndrome. Dirk and his colleagues also worked on identifying and purifying normal haematopoietic stem cells, developing animal models of experimental therapies in acute myeloid leukaemia and many other topics.

If you are allowed only one book in your transplant library, make it The Radiation Chimeras by Dirk van Bekkum and Marco de Vries first published in 1967.' (Interestingly Radiation Chimeras was published by Logos Press. Logos has two definitions: (1) the rational principle that governs and develops the universe; and (2) the divine word or reason incarnate in Jesus Christ (John 1:1-14). We are unsure which better defines this book.) Radiation Chimeras is The Bible. It describes the fundamentals of bone marrow transplantation, the concept of haematopoietic chimerism and the biology of GvHD. In Chapter VI, 'Clinical applications of bone marrow transplantation and related experiments', the authors presciently outline possible clinical applications: (1) treatment of haematopoietic failure following irradiation; (2) autologous bone marrow after chemotherapy; (3) whole-body irradiation and transplantation of haematopoietic cells in the experimental treatment of leukaemia; (4) attempts to control the graft versus tumour reaction; (5) complications of the treatment other than secondary disease (GvHD); (6) clinical application of bone marrow transplantation in the treatment of leukaemia; (7) treatment of other blood diseases with bone marrow; and (8) production of chimeras as a preparation for organ transplantation. That covers the bases describing nicely where we are today almost 50 years later! To quote Ecclesiastes (1:4-11).

Is there a thing of which it is said, 'See, this is new'? It has been already in the ages before us.

At Leukemia we have special affection for Dirk. He was a close colleague of our founders Sven-Aage Killman and Nicole Muller-Bérat, who spent a sabbatical year in his laboratory at the

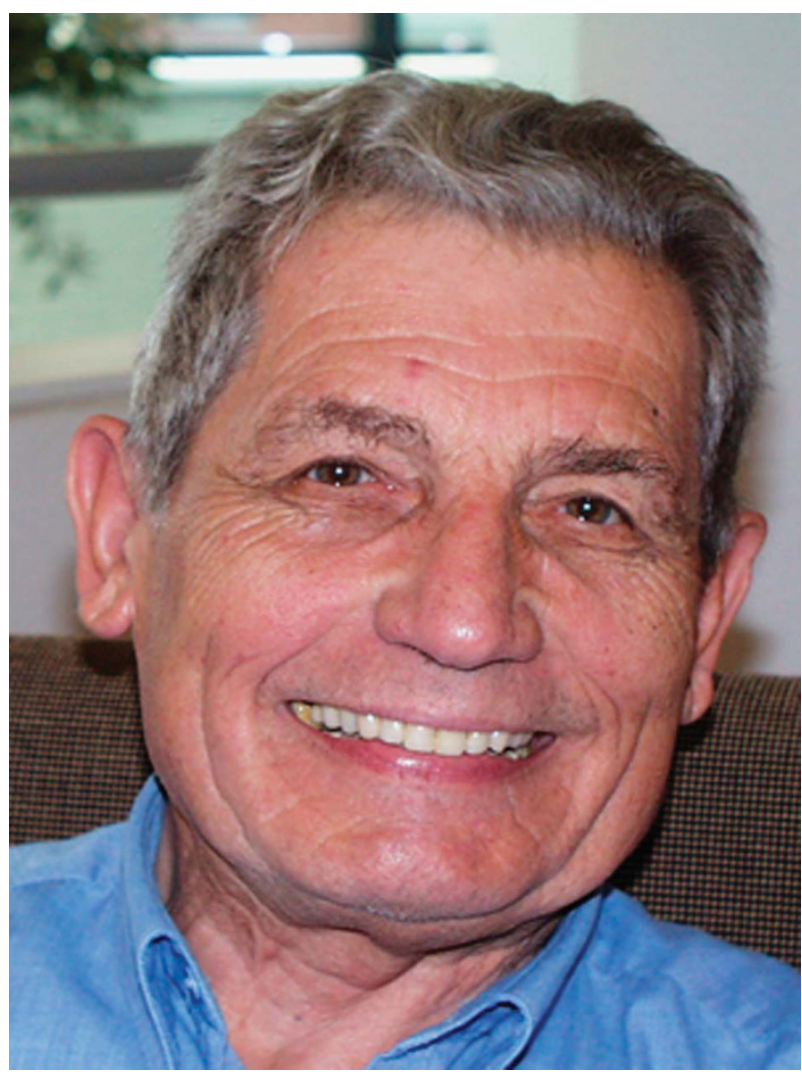

Radiobiological Institute of TNO in Rijswijk. Dirk was an honorary member of the Leukemia Editorial Board since the Journal's inception.

It is impossible to mention all of Dirk's colleagues, students, mentees and friends who went on to do great things in haematology, transplantation and radiobiology. He worked during many years with international collaborators: Ramond Bradley, Georges Mathé, George Santos, Theodor Fliedner, Donald Metcalf, Mortimer Bortin, Dov Pluznik and Eugene Cronkite, to name a few.

Dirk's personality was unique. You had to have worked with or met him frequently to fully appreciate it. He was a walking, rapidly talking (Siri had nothing on him) encyclopedia of transplantation biology who could recall details of experiments done decades earlier. At first it seemed a huge mistake to challenge Dirk on any relevant scientific point. First, you were likely to be wrong. Second, he did not suffer fools lightly. In reality he liked the challenge of debate in the interest of the scientific question at issue and he would challenge any discussion partner regardless their position. Importantly, and uncommonly, he was direct, straight and always open to a critical discussion. Beneath it all he was kind, warmhearted and encouraging to students, colleagues and friends. He coaxed, cajoled and sometimes forced people to do their very best.

How could The Netherlands with a population of less than 16 million produce so many distinguished haematologists and 
experimental biologists prominent in transplantation, leukaemia therapy and other fields? Does much of the credit go to Dirk van Bekkum? Readers of Leukemia will be familiar with three relevant concepts: (1) a stem cell able to self-renew and give rise to differentiated progeny; (2) the hierarchical structure of haematopoiesis; and (3) a founder effect. All three apply to Dirk. He started with a small research group at the Radiobiology Institute of the TNO in Rijswijk funded by the Dutch government, which was concerned with protecting the military and the public from radiation-induced bone marrow failure. Interestingly, Dirk had studied biochemistry at Oxford with Sir Rudolph Peters, who developed British anti-lewisite (dimercaprol), an antidote to Lewisite (acetylene and arsenic trichloride) for chemical warfare. In 1952 he completed his PhD thesis in Leiden cum laude on D-amino-acid oxidase. Legend has it Dirk, as a PhD student, felt he needed more laboratory bench space. As soon as his Professor left for 6 months for a sabbatical abroad, Dirk devised a creative solution. On his return, the Professor found his office transformed to a lab.

At the Radiobiological Institute in Rijswijk, Dirk frequently served rijstaffel before a seminar, perhaps reflecting his birth in the Dutch East Indies (now Indonesia). It was a great hit.

Dirk made many other important contributions and received many honours. He was an elected member of the Dutch Royal Academy of Arts and Sciences and a Knight of the Royal Order of the Lion of the Netherlands, a founder of the European Organization for Research on Treatment of Cancer, European Bone Marrow Transplantation Group, the International Bone Marrow Transplantation Registry (now CIBMTR), the International Society of Experimental Hematology and the Dutch Society of Immunology, recipient of a Fogarty Scholarship from the US National Institutes of Health and an honorary member of the Dutch Society of Gene Therapy and Cell Biology.

At age 85, Dirk, full of energy, started Cinderella Therapeutics, a non-profit organization. He had become increasingly concerned about access to effective therapies in light of the extraordinary cost of new drugs. Ten days before he died he sent an e-mail to Bob Löwenberg: 'Bob, I would like to talk with you again about this subject because I have an idea to start producing some of these drugs ourselves at Cinderella.' When Bob went to his home he found Dirk working in his vegetable garden. He was as vital and bright as always and in a determined, fighting spirit. (He was always trying to transform the world.) Bob had no clue this would be his final conversation with Dirk after a friendship of 45 years.

Back to Dirk and haematopoietic stem cells. We make about 200 billion RBCs per day. Stem cell Dirk was not far behind in generating progeny: he is survived by his wife Ada, 4 daughters, 11 grandchildren and 7 great grandchildren (so far).

In the preface to Radiation Chimeras, van Bekkum and de Vries commented on why they thought many clinical trials of good but unproved hypotheses fail: '...mainly because the clinical applications were undertaken too soon, most of them before even the minimum of basic knowledge required to bridge the gap between mouse and patient'. This remains so today.

Robert Peter Gale ${ }^{1}$ and Bob Löwenberg ${ }^{2}$

${ }^{1}$ Imperial College London, London, UK and

${ }^{2}$ Erasmus University Medical Center, Rotterdam, The Netherlands

E-mail: robertpetergale@gmail.com orb.lowenberg@erasmusmc.nl

\section{REFERENCES}

1 van Bekkum DW, de Vries MJ. Radiation Chimaeras. Radiobiological Institute of the Organisation of Health Research TNO: Rijswijk, Zuid Holland, The Netherlands. Originally published by Logos Press: London, and Academic Press: New York and London, 1967. 